\title{
Canonical Word Order of Japanese Ditransitive Sentences: A Preliminary Investigation through a Grammaticality Judgment Survey
}

\author{
Yasumasa Shigenaga \\ The University of Arizona \\ E-mail: yshigena@email.arizona.edu
}

Doi:10.7575/aiac.alls.v.5n.2p.35

Received: 11/02/2014

URL: http://dx.doi.org/10.7575/aiac.alls.v.5n.2p.35

Accepted: 24/03/2014

\begin{abstract}
There have been three competing analyses regarding the canonical word order of Japanese ditransitive sentences: a) "S$g a$ IO- $n i$ DO- $o$ V" is the canonical word order rather than "S-ga DO-o IO- $n i \mathrm{~V}$ ", b) both word orders are canonical, and c) the canonical word order depends on the type of the verb. The present study attempted to examine which of the three analyses might be most plausible through a grammaticality judgment survey. Twenty-seven native speakers of Japanese responded to a survey which consisted of three sections. While the data from one of the sections conformed to analysis a) above, the results of the two other sections remained inconclusive. A future study with a larger number of items and more refined survey methods, along with more studies from structural and psycholinguistic perspectives, would be necessary to clarify the point.
\end{abstract}

Keywords: word order, scrambling, Japanese, grammaticality judgment

\section{Introduction}

As each noun phrase is often case-marked in a Japanese sentence, Japanese allows so-called scrambling, a freer word order phenomenon. For a simple transitive sentence such as Subject-ga Object- $o$ Verb, native speakers of Japanese have a strong intuition that "S-ga O-o V" is the canonical word order and that a sentence with the "O-o S-ga V" order is derived from the canonical order. On the other hand, the canonical word order of ditransitive sentences in Japanese appears less clear. Which is the canonical ditransitive word order, "S- $g a$ Indirect Object- $n i$ Direct Object- $o$ V" or "S-ga DO-o IO- $n i \mathrm{~V}$ "? A small survey was conducted to examine the issue.

This paper first provides the general theoretical background for the phenomenon of scrambling in Japanese. It then reviews three major competing analyses on Japanese ditransitive constructions and the arguments researchers have presented to support their analyses. The results of the survey will then be reviewed, and the implications of the survey results on canonical word order of Japanese ditransitive sentences will be discussed.

\subsection{Scrambling in Japanese}

For monotransitive Japanese sentences, the canonical word order is Subject (S) - Object (O) - Verb (V). However, since each noun phrase (NP) in a sentence is often case-marked with postpositional case markers, Japanese does allow a freer word order. The exception is the verb, which needs to be placed at the end of the clause. The sentences (1a) and (1b) are both grammatical sentences; (1a) being the canonical sentence and (1b) the scrambled.

$$
\begin{array}{lll}
\text { a. John-ga ringo-o } & \text { tabeta. } \\
\text {-Nom apple-Acc } & \text { ate } \\
\text { 'John ate an apple.' } & \\
\text { b. Ringo-o John-ga } & \text { tabeta. } \\
\text { Apple-Acc } \quad \text {-Nom ate }
\end{array}
$$

Note that both (1a) and (1b) carry exactly the same meaning, 'John ate (an) apple(s).', with slight emphasis on the word-initial apple in (1b).

\subsection{Structure of scrambling}

In earlier analyses, scrambling was taken as evidence that Japanese has a non-configurational "flat" structure without a VP node (e.g., Farmer, 1984; Hale, 1980). Currently, on the other hand, the standard analysis of scrambling is that a scrambled sentence such as (1b) above is derived from the canonical counterpart (e.g., Saito \& Hoji, 1983). The structure of the sentences in (1) would look like the following:

$$
\begin{aligned}
& \text { a. [IP John-ga [VP ringo-o tabeta]] } \\
& \text { b. [IP Ringo }{ }_{i} \text {-o [IP John-ga [VP } \mathrm{t}_{i} \text { tabeta]]] }
\end{aligned}
$$

Note in (2b) that an additional IP node is adjoined to the syntactic tree, and that the accusative NP ringo-o ('apple') is 
moved higher in the tree, leaving a trace.

The evidence for the existence of a VP node includes such syntactic phenomena as pronominal coreference (Saito, 1985), weak crossover (Saito \& Hoji, 1983), and quantifier floating (Saito, 1985) (cf., Nemoto, 1999, for overview). Saito (1985), for instance, maintains that the binding rule, "A pronoun cannot c-command its antecedent" (p. 36) cannot be fulfilled if the existence of a VP node is not assumed. Below are examples used in Saito (1985: 37 ).

$$
\begin{aligned}
& \text { a. } \mathrm{John}_{\mathrm{i}} \text {-ga [Mary-ga kare }{ }_{\mathrm{i}} \text {-ni okutta tegami]-o mada yonde inai (koto) } \\
& \text {-Nom -Nom he-Dat sent letter-Acc yet read not } \\
& \text { 'John has not yet read the letter Mary sent him.' } \\
& \text { b. *Kare }{ }_{\mathrm{i}} \text {-ga [Mary-ga } \mathrm{John}_{\mathrm{i}} \text {-ni okutta tegami]-o mada yonde inai (koto) } \\
& \text { he-Nom -Nom -Dat sent letter-Acc yet read not } \\
& \text { 'He has not yet read the letter Mary sent John.' } \\
& \text { c. [ } \mathrm{John}_{\mathrm{i}} \text {-kara okane-o moratta hito]-ga kare } \mathrm{i}_{\mathrm{i}} \mathrm{o} \text { suisensita (koto) } \\
& \text {-from money-Acc received person-Nom he-Acc recommended } \\
& \text { 'The person who received money from John recommended him.' } \\
& \text { d. [Kare }- \text { kara okane-o moratta hito]-ga John }{ }_{\mathrm{i}-\mathrm{O}} \text { suisensita (koto) } \\
& \text { He-from money-Acc received person-Nom -Acc recommended } \\
& \text { 'The person who received money from him recommended John.' }
\end{aligned}
$$

Saito (1985) argues that, if the existence of a VP is not assumed in Japanese, as proposed in the "flat" analysis, (3c) should be ungrammatical just as ( $3 b)$ is. This would be so because, without a VP, kare ('he') would c-command its antecedent John in (3c). However, (3c) is a well-formed sentence in Japanese. Saito (1985) attributes this asymmetry between the subject NP and object NP to the existence of a VP. (3d) shows that a pronominal can precede its antecedent in Japanese.

That Japanese does not have a flat structure (i.e., that it has a canonical word order) can also be observed with examples such as below (the examples are from Yamashita 2002: 601-602).

$$
\begin{array}{cccc}
\text { a. John-ga } & \text { Mary-ni } & \text { ringo-o } & \text { ageta. } \\
\text {-Nom } & \text {-Dat } & \text { apple-Acc } & \text { gave } \\
\text { 'John gave } & \text { Mary an apple.' } & \\
\text { b. Mary-ni } & \text { John-ga } & \text { ringo-o } & \text { ageta. } \\
\text {-Dat } & \text {-Nom } & \text { apple-Acc } & \text { gave } \\
\text { c. Ringo-o } & \text { John-ga } & \text { Mary-ni } & \text { ageta. } \\
\text { Apple-Acc } & \text {-Nom } & \text {-Dat } & \text { gave } \\
\text { d. ?Mary-ni } & \text { ringo-o } & \text { John-ga } & \text { ageta. } \\
\text {-Dat } & \text {-Acc } & \text {-Nom } & \text { gave } \\
\text { e. ?Ringo-o } & \text { Mary-ni } & \text { John-ga } & \text { ageta. } \\
\text { Apple-Acc } & \text {-Dat } & \text {-Nom } & \text { gave }
\end{array}
$$

(4a) is a sentence with a canonical word order. If Japanese had a flat structure, all the sentences in (4) would show the same degree of grammaticality. However, while (4a)-(4c) are well-formed sentences in Japanese, (4d) and (4e) are only marginally grammatical. As Shibatani (1990) points out, scrambling two or more constituents results in reduced grammaticality. Examples such as above show that scrambling is not a totally free operation.

\section{Three analyses on canonical word order of Japanese ditransitive sentences}

When the argument of a sentence precedes the NP marked with $-g a$, as in (1b) and (4b-e), it is intuitively clear that scrambling has taken place. Most native speakers of Japanese would agree that (1b) derived from (1a), and (4c) derived from (4a) or its " $-o-n i$ " order equivalent. On the other hand, many native speakers of Japanese would experience difficulty if they are asked which of the following two sentences represents the canonical word order:

$$
\begin{gathered}
\text { a. Taroo-ga sensei-ni gakusei-o syookaisita. } \\
\text {-Nom teacher-Dat student-Acc introduced } \\
\text { 'Taroo introduced the student to the teacher.' } \\
\text { b. Taroo-ga gakusei-o sensei-ni syookaisita. } \\
\text {-Nom student-Acc teacher-Dat introduced }
\end{gathered}
$$

Corresponding to this somewhat "fuzzy" intuition, there are three major competing analyses on the canonical order of Japanese ditransitive sentences. The three analyses can be briefly summarized as follows:
A: "Dative- $n i$ Accusative- $o$ " is the canonical word order
B: Both "Dat-ni Acc-o" and "Acc-o Dat-ni" orders are base-generated
C: The canonical word order depends on the type of the verb

\subsection{Analysis A: "Dat-ni Acc-o" is the canonical order}

Hoji (1985) and Takano (1998), among others, argue that the base-generated order is dative-accusative and that the accusative-dative word order is derived by scrambling. Key evidence that Hoji (1985) and Takano (1998) employ to 
support their argument is the following (Takano, 1998: 828):
a. Mary-ga
subete-no gakusei $i_{i}$-ni
soitu $\mathrm{i}_{\mathrm{i}}$-no sensei-o
syookaisita
Mary-Nom all-Gen student-Dat he-Gen teacher-Acc introduced
'Mary introduced his teacher to every student.'

b. *Mary-ga soitu $\mathrm{i}_{\mathrm{i}}$-no sensei-ni subete-no gakusei $\mathrm{i}_{\mathrm{i}}-\mathrm{o}$ syookaisita Mary-Nom he-Gen teacher-Dat all-Gen student-Acc introduced

c. Mary-ga [subete-no gakusei $]_{\mathrm{i}} \mathrm{-o} \quad$ soitu $_{\mathrm{i}}$-no sensei-ni $t_{\mathrm{i}} \quad$ syookaisita Mary-Nom all-Gen student-Acc he-Gen teacher-Dat introduced

'Mary introduced every student to his teacher.'

d. ?Mary-ga $\quad\left[\text { soitu }_{\mathrm{i}} \text {-no sensei-o }\right]_{\mathrm{j}} \quad$ subete-no gakusei $_{\mathrm{i}}-\mathrm{ni} t_{\mathrm{j}}$ syookaisita Mary-Nom he-Gen teacher-Acc all-Gen student-Dat introduced

According to Saito and Hoji (1983), "A variable cannot be the antecedent of a pronoun or anaphor that it does not ccommand" (p. 256). (7a) and (7c) are grammatical because the pronoun soitu is properly c-commanded by the antecedent subete-no gakusei. On the other hand, (7b) is not acceptable because the pronoun in the dative NP is not ccommanded by subete-no gakusei in the accusative NP.

Hoji and Takano claim that (7d) is not completely grammatical but is more acceptable than (7b). The researchers attribute this better acceptability of $(7 \mathrm{~d})$ to the reconstruction effect at LF. At S-structure, the pronoun soitu precedes subete-no gakusei, and thus, subete-no gakusei in the accusative NP cannot be the antecedent of soitu. However, if we assume that the dative-accusative order is base-generated and that the accusative-dative order of ( $7 \mathrm{~d}$ ) is derived from (7a) via scrambling, a trace should be left where the accusative NP originated. The trace is c-commanded by the accusative NP which includes the antecedent. Hoji and Takano maintain that the better grammaticality of $(7 \mathrm{~d})$ is gained because the accusative NP can be placed back to the trace position at LF. Note that if we assume that accusative-dative order is base generated, the opposite prediction about the grammaticality of (7b) and (7d) would be expected.

\subsection{Analysis B: Both “Dat-ni Acc-o” and “Acc-o Dat-ni” orders are base-generated}

Miyagawa (1997) and Kitagawa (1994) maintain that both dative-accusative and accusative-dative orders are basegenerated. Evidence that Miyagawa (1997) employs to support his argument is the Chain Condition. After confirming that Japanese observes Rizzi's (1986) Chain Condition using IP-adjunction scrambling sentences, Miyagawa presents the following example (p. 5):

$$
\begin{array}{llll}
\text { ?John-ga } & \text { [Hanako-to Mary }]_{\mathrm{i}}-\mathrm{o} \quad \text { (party-de) otagai } \mathrm{i}_{\mathrm{i}}-\mathrm{ni}\left(t_{\mathrm{i}}\right) & \text { syookaisita } \\
\text { John-Nom Hanako-and Mary }- \text { Acc } & \text { party-at each other }- \text { Dat introduced } \\
\text { 'John introduced Hanako and Mary to each other at the party.' }
\end{array}
$$

If the sentence above was derived by scrambling, there would be a trace which would be locally c-commanded by the reciprocal anaphor, otagai, and thus Chain Condition violation would be expected. However, the sentence is acceptable. Miyagawa (1997) sees this as evidence that there is no trace in the sentence and that the accusative-dative word order (as well as the dative-accusative order) is base-generated.

Miyagawa (1997) further argues that $-n i$ in $-n i-O$ order is a dative case marker while $-n i$ in $-o-n i$ order is postposition. Miyagawa maintains, based on previous studies (e.g., Haig, 1980), that a floating numeral quantifier is possible if the associated NP is case-marked, while it is not possible if the NP has a postposition. Miyagawa observes that $(9 a)$ is grammatical while the acceptability of $(9 b)$ is significantly lower.

$$
\begin{aligned}
& \text { a. Mary-ga tomodati-ni futa-ri CD-o okutta. } \\
& \text { Mary-Nom friend-Dat 2-CL CD-Acc sent } \\
& \text { Mary sent two friends a CD.' }
\end{aligned}
$$

$$
\begin{aligned}
& \text { b. ???Mary-ga CD-o tomodati-ni futa-ri okutta. } \\
& \text { Mary-Nom CD-Acc friend 2-CL sent }
\end{aligned}
$$

(Miyagawa, 1997: 9)

Based on the grammaticality observation, Miyagawa claims that $-n i$ in (9a) is a dative case marker while $-n i$ in (9b) is a postposition. (9a) is grammatical because the numerical quantifier futa-ri is associated with the case-marked NP tomodati-ni. On the other hand, (9b) is not as acceptable because the numerical quantifier is associated with the NP marked by a postposition.

\subsection{Analysis $C$ : The canonical word order depends on the type of the verb}

Matsuoka (2003) maintains that there are two types of ditransitive verbs in Japanese. According to Matsuoka, the first type (pass-type) base-generates the accusative-dative order while the second type (show-type) base-generates the dative-accusative word order.

Matsuoka supports his argument using the inchoative variants of the ditransitive verbs. Observe the following examples provided in Matsuoka (2003: 173, 187).

$$
\begin{gathered}
\text { a. John-ga hanataba-o Mary-ni } \quad \text { wata-s(i)-ta. } \\
\text {-Nom bouquet-Acc } \\
\text { 'John passed a bouquet to Mary.' } \\
\text { b. Hanataba-ga Mary-ni wata-r-ta. } \quad \text { (wata-r-ta } \rightarrow \text { watatta) }
\end{gathered}
$$


A bouquet -Nom -Dat pass-Inc-Past

c. *Mary-ga hanataba-o wata-r-ta.

-Nom bouquet-Acc pass-Inc-Past

'Mary got a bouquet passed to her $_{i}$ '.

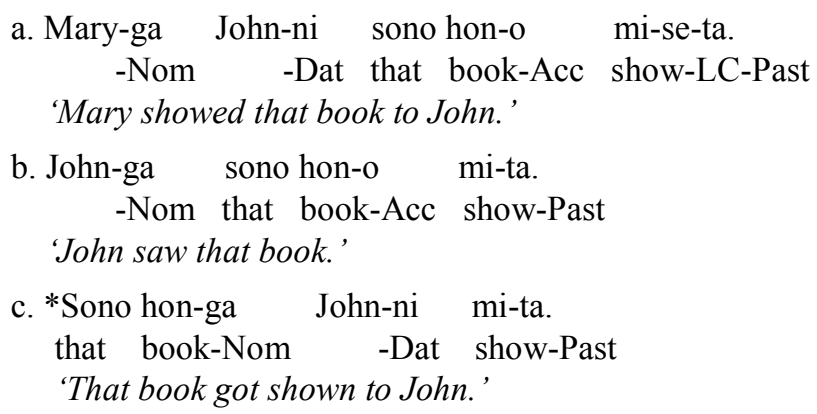

Watasita in (10a) is the past-tense form of the ditransitive verb watasu, and watatta in (10b \& c) is the past-tense form of its inchoative variant wataru. Likewise, miseta in (11a) is the past-tense form of the ditransitive verb miseru, and mita in $(11 \mathrm{~b} \& \mathrm{c})$ is the past-tense form of its inchoative variant miru. As shown in (10a) and (11a), both watasu and miseru form a ditransitive construction in a similar manner - both select three arguments: nominative, dative, and accusative NPs, case-marked with $-g a$, $-n i$, and $-o$, respectively. A crucial difference appears in (10b) and (11b). While wataru chooses the accusative case-marked NP (hanataba) of the ditransitive sentence as its subject, miru chooses the dative case-marked NP (John) of the ditransitive sentence as its subject. The dative case-marked NP (Mary) cannot become the subject of wataru as shown in (10c), and the accusative case-marked NP (sono hon) cannot become the subject of miru as in (11c). Thus, Matsuoka observes that there are two different types of ditransitive verbs in Japanese, pass-type (10) and show-type (11). (Note 1)

Matsuoka (2003) maintains, based on the discussion by Baker (1995), that the difference observed in the inchoative variants between the two types of verbs reflects a difference in the base-generated positions of dative and accusative arguments. That is, a pass-type verb projects the accusative argument higher in the tree than the dative argument while a show-type verb projects the dative argument in a higher position than the accusative argument. Matsuoka employs the Minimal Link Condition (MLC) (Chomsky, 1995) to account for the selection of nominative arguments in the inchoative sentences.

$$
\begin{aligned}
& \text { Minimal Link Condition } \\
& \mathrm{K} \text { attracts } \alpha \text { only if there is no } \beta, \beta \text { closer to } \mathrm{K} \text { than } \alpha \text {, such that } \mathrm{K} \text { attracts } \beta . \quad \text { (Chomsky, 1995: 311) }
\end{aligned}
$$

Tree structures of (10b) and (11b) are provided in (13) below (adopted from Matsuoka, 2003: 175, 195):

(13)

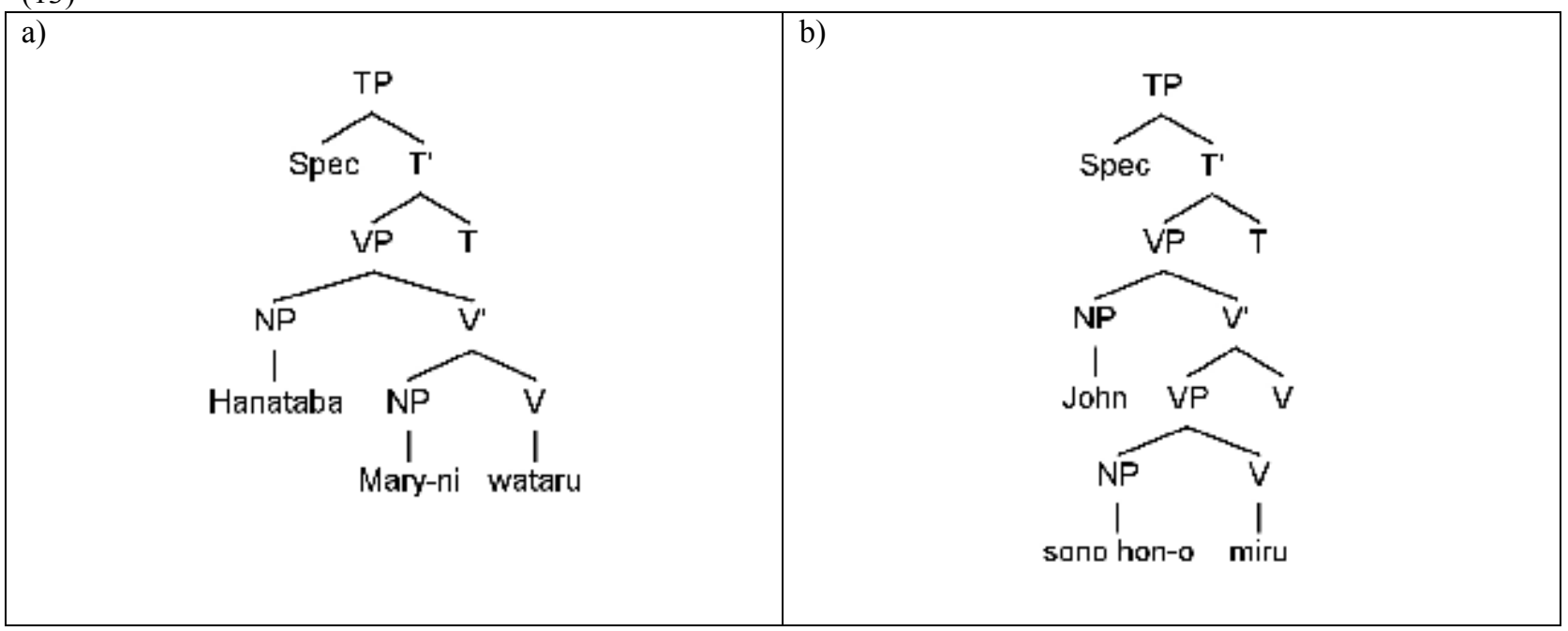

In (13a), since watatta (the past tense form of wataru) is an unaccusative verb, it cannot assign an accusative case to hanataba. However, because $\mathrm{T}$ can assign a nominative case, it searches for the closest NP, and thus, hanataba is attracted to the Spec TP position. If we assume that the dative NP is base-generated higher than the accusative NP, Mary would be promoted to the Spec TP position, which would cause ungrammaticality shown in (10c). Likewise, in (13b), mita (the past-tense form of miru) cannot assign a dative case to John because it is a (mono)transitive verb. Thus the argument which is closest to T (John) is attracted for case and is promoted to the Spec TP position. Again, if we assume that the accusative NP sono hon is base-generated higher in the tree than the dative NP John, sono hon instead of John would be attracted by $\mathrm{T}$, causing the ungrammaticality shown in (11c).

Matsuoka (2003) further argues that, in terms of theta role, the dative argument of a pass-type verb is the goal while the dative argument of a show-type verb is the experiencer. In (10a), for instance, the dative NP Mary refers to the end point 
to which the theme (bouquet) moves. In this sense, the dative argument of a pass-type verb is interpreted as the goal. On the other hand, Matsuoka points out that the dative argument of a show-type verb does not necessarily specify the end point to which the theme goes. In (11a), it is possible to picture a situation in which John is looking at the book in his hands, while it is also possible to imagine a situation where Mary shows the book to John with the book in her hands. Thus, the dative argument of a show-type verb is interpreted as the experiencer.

Related to the theta-role distinction above, Matsuoka points out Matsumoto's (2000) observation that show-type verbs typically select an animate NP for the dative argument, while the dative arguments of pass-type verbs are more often inanimate. The example (14) cited from Matsuoka (2003: 190) illustrates this point. Kaketa is the past-tense form of a pass-type verb kakeru, and abiseta is the past-tense form of a show-type verb abiseru. The sentence with kaketa (14a) quite naturally takes the inanimate dative NP kabe ('wall'), but (14b) with abiseta is quite marginal, although both verbs are quite similar in terms of their meanings.

$$
\begin{aligned}
& \text { a. Taroo-ga kabe-ni penki-o kak-e-ta. } \\
& \text { Taro-Nom wall-Dat paint-Acc put on-LC-Past } \\
& \text { 'Taro put paint on the wall.' } \\
& \text { b. ?*Taroo-ga kabe-ni penki-o abi-se-ta. } \\
& \text { Taro-Nom wall-Dat paint-Acc pour-LC-Past } \\
& \text { 'Taro poured paint over the wall.' }
\end{aligned}
$$

\section{Psycholinguistic studies on Japanese scrambled sentences}

Which of the three analyses above is the correct one? Psycholinguistic studies on scrambled sentences may provide a clue. It has been confirmed in sentence processing studies that scrambled sentences are associated with additional psychological cost. Mazuka, Itoh, \& Kondo (2002), for instance, compared the processing of the following two sentences, using two methods - eye tracking and self-paced reading.

(15) a. Canonical sentence with a center embedding: [NP-ga [modifier phrase] NP-o V]

b. Scrambled sentence with a center embedding: [NP-o [modifier phrase] NP-ga V]

The eye-tracking experiment as well as the self-paced reading experiment indicated that the sentences with canonical word order (15a) were read significantly faster than their scrambled counterparts (15b). If scrambling is indeed associated with additional processing cost (thus, a longer reading time), it will provide a very important clue to the canonical order of ditransitive sentences.

Tamaoka et al. (2005) examined the influence of scrambling on reading time and error rates, using different types of sentences. In Experiment 2 of their study, Tamaoka et al. examined the reading time of the following two types of sentences:

a. Canonical word order: NP-ga NP-ni NP-o V.

b. Accusative NP fronted: NP-o NP-ga NP-ni V.

Each sentence was displayed on a computer screen, and the participants were asked to decide as quickly as possible whether or not the sentence was correct. The result indicated that the processing of scrambled sentences took longer reaction times and resulted in higher error rates than the canonical sentences. Although the experiment did not test the Dat-Acc/Acc-Dat word order that we are interested in here, the result is of interest in that it confirmed scrambling effects are also present in ditransitive sentences.

In Experiment 5 of the same study, Tamaoka et al. tested the processing of causative sentences. In doing so, they used two types of verbs - transitive verbs taking an accusative object (accusative verbs) and transitive verbs taking a dative object (dative verbs).

(17) Accusative verb
Pupil-Nom atelier-Acc built
'The pupil built the atelier.'
a. Deshi-ga atorie-o tukutta.
b. Junko-ga deshi-ni atorie-o tsukur-ase-ta.
-Nom pupil-Dat atelier-Acc build-Cause-Past
'Junko made her pupil build the atelier.'
c. Junko-ga atorie- $\mathrm{o}_{\mathrm{i}}$ deshi-ni $t_{\mathrm{i}}$ tsukur-ase-ta. -Nom atelier-Acc pupil-Dat built-Cause-Past

(18) Dative verb
a. Deshi-ga atorie-ni komotta.
Pupil-Nom atelier-Dat stayed
'The pupil shut himself up in the atelier.'
b. Junko-ga deshi-o atorie-ni komor-ase-ta.
-Nom pupil-Acc atelier-Dat stay-Cause-Past
'Junko made her pupil shut himself up in the atelier.'
c. Junko-ga
atorie-ni $\mathrm{i}_{\mathrm{i}}$ deshi-o
$t_{\mathrm{i}}$ komor-ase-ta. 


-Nom atelier-Dat pupil-Acc stay-Cause-Past

Based on the grammatical function hierarchy 'Subject $>$ Indirect Object $>$ Direct Object', Tamaoka et al. assume that (17b) and (18b) are the canonical word order of causative sentences with accusative verb and dative verb, respectively. Note that the dative NP is projected higher than the accusative NP in (17b), while the order is opposite in (18b). (17c) and (18c) are their scrambled counterparts. If scrambled sentences are indeed associated with psychological processing cost, and if (17b) and (18b) indeed represent the canonical word orders of causative sentences, (17b) should be processed faster and more accurately than (17c), and (18b) faster and more accurately than (18c).

The results of Experiment 5 demonstrated this exactly. As for processing speed, accusative verb sentences with dativeaccusative order were read significantly faster than accusative-dative sentences, while dative verb sentences with accusative-dative order were read significantly faster than dative-accusative sentences. As for error rates, the results indicated that accusative verb sentences with dative-accusative order were processed more accurately than those with accusative-dative order, and the results were reversed for dative verb sentences, as expected. Thus, the results seem to strongly suggest that faster processing speed is associated with the canonical order of sentences and that processing of causative sentences relies more on canonical word order (grammatical functions) than on surface dativeaccusative/accusative-dative case marking.

Koizumi and Tamaoka (2004) directly examined the three analyses discussed above in terms of processing speed. If canonical word order yields faster processing speed, the following will be predicted about the three analyses:

$$
\begin{array}{ll}
\text { a. Hoji (1985): } & \text { Dat-Acc }<\text { Acc-Dat } \\
\text { b. Miyagawa (1997): } & \text { Dat-Acc = Acc-Dat } \\
\text { c. Matsuoka (2003): } & \text { Pass-type verbs: Acc-Dat }<\text { Dat-Acc } \\
& \text { Show-type verbs: Dat-Acc }<\text { Acc-Dat }
\end{array}
$$

(Koizumi \& Tamaoka, 2004: 177)

For Hoji (1985), a dative NP is always base-generated higher than an accusative NP, and thus, the processing speed of dative-accusative ditransitive sentences should be faster than that of accusative-dative sentences, regardless of verb types. Miyagawa (1997) analyzes that both dative-accusative and accusative-dative word orders are base-generated. Therefore, according to this analysis, the processing speed of the two types of sentences should not be significantly different. Finally, if Matsuoka (2003) is correct, it is expected that the processing speed is faster for the accusativedative order with pass-type verbs, while the dative-accusative word order is expected to be processed faster with showtype verbs.

In Koizumi and Tamaoka (2004), each sentence was presented on a computer screen, and the participants were asked to make a judgment as quickly as possible whether or not the sentence presented was correct. The results indicated that sentences with the dative-accusative order were processed faster, regardless of verb types. Given the implication of Tamaoka et al. (2005) that the processing speed of sentences reflects the canonical word order rather than surface case markings, Koizumi \& Tamaoka's (2004) results seem to suggest that the "NP-ga NP-ni NP-o V" order represents the canonical word order of Japanese ditransitive sentences, conforming to Hoji's (1985) analysis.

\section{A short survey study}

While Koizumi \& Tamaoka's (2004) sentence processing study strongly suggests that the dative-accusative order is the canonical word order for Japanese ditransitive sentences, results of online psycholinguistic studies, in general, can be easily influenced by the particular items used. Thus, in the hope of deepening our understanding of the nature of the canonical word order in Japanese ditransitive sentences, and possibly triangulating the syntactic analyses and the results of the psycholinguistic studies, a short survey of grammaticality judgment was conducted.

\subsection{Designs and procedures}

The survey consisted of three sections. The first section was aimed at examining Miyagawa's (1997) analysis that $n i$ in $-n i-O$ order is a dative case marker while $-n i$ in $-O-n i$ order is a postposition. Miyagawa's analysis was based on the grammaticality of sentences with a floating numeral quantifier as in (9) above. Thus, in the first section of the survey, the grammaticality of sentences similar to (9) was assessed. Below are examples of the sentences:

$$
\begin{aligned}
& \text { a. Mary-ga tomodati-ni futa-ri CD-o watashita. } \\
& \text {-Nom friend-Dat 2-CL CD-Acc passed } \\
& \text { 'Mary passed CDs to two friends.' } \\
& \text { b. Mary-ga CD-o tomodati-ni futa-ri watashita. } \\
& \text {-Nom CD-Acc friend-Dat 2-CL passed }
\end{aligned}
$$

The participants were asked to evaluate the grammaticality of sentences using a 5-point Likert scale: 5 (No problems as a Japanese sentence); 4 (Somewhat strange as a Japanese sentence, but still acceptable); 3 (neutral); 2 (Not totally unacceptable, but quite strange); 1 (totally unacceptable as a Japanese sentence). If $-n i$ in (20a) and (20b) have different status, as Miyagawa maintains, sentences of (20a) type and (20b) type should receive different degrees of grammaticality judgment.

In order to examine if the pass/show-type dichotomy might influence grammaticality judgments, three pass-type verbs and three show-type verbs were used to create sentence items. The pass-type verbs used were watasu ('pass'), butukeru ('throw'), kaesu ('return'), and the show-type verbs used were miseru ('show'), azukeru ('entrust'), and kasu ('lend'). Since there were scrambled counterparts for each of the six verbs, each participant was asked to assess the 
grammaticality of twelve sentences in the first section.

The next section attempted to examine Hoji (1985) and Takano's (1998) analysis that the "dative- $n i$ accusative- $o$ " is the canonical word order. Takano's example (7) is repeated below: Mary-Nom all-Gen student-Dat he-Gen teacher-Acc introduced 'Mary introduced his teacher to every student.'
a. Mary-ga subete-no gakusei ${ }_{i}-n i \quad$ soitu $_{\mathrm{i}}$-no sensei-o syookaisita
b. *Mary-ga soitu $\mathrm{i}_{\mathrm{i}}$-no sensei-ni subete-no gakusei $_{\mathrm{i}}-\mathrm{O}$ syookaisita Mary-Nom he-Gen teacher-Dat all-Gen student-Acc introduced
c. Mary-ga [subete-no gakusei $]_{\mathrm{i}-\mathrm{O}} \quad$ soitu $_{\mathrm{i}}-$ no sensei-ni $t_{\mathrm{i}} \quad$ syookaisita Mary-Nom all-Gen student-Acc he-Gen teacher-Dat introduced 'Mary introduced every student to his teacher.'
d. ?Mary-ga [soitu $\mathrm{i}_{\mathrm{i}}$-no sensei-o $]_{\mathrm{j}} \quad$ subete-no gakusei $\mathrm{i}_{\mathrm{i}}-\mathrm{ni} t_{\mathrm{j}}$ syookaisita Mary-Nom he-Gen teacher-Acc all-Gen student-Dat introduced

Hoji and Takano see ungrammaticality in the "anaphor- $n i$ antecedent- $o$ " order (21b) and marginal acceptability in the "anaphor- $o$ antecedent- $n i$ " order (21d), and their analysis of the canonical word order of ditransitive sentences is partly based on this observation. Therefore, grammaticality of sentences similar to (21) was evaluated in the second section of the survey.

In this part of the survey, instead of asking the participants whether the sentences were grammatical, they were asked to choose what the anaphor referred to in a given sentence. Thus, for (21a), for instance, the participants were prompted to choose one of the multiple choice items - e.g., "soitu in the sentence refers to... a) subete-no gakusei, b) someone other than subete-no gakusei, c) both subete-no gakusei and one or more other people." This method was chosen because coindexation was likely to cause confusion to participants who were not familiar with the notation. If the anaphors of (21d) type sentences are judged to refer to the antecedents more often than those of (21b) type sentence items, it will probably support Hoji's analysis that the "dative- $n i$ accusative- $o$ " order is base-generated. If, on the other hand, the anaphors of (21d) type sentences are judged to refer to the antecedents no more often than those of (21b) type sentence items, it may support Miyagawa's (1997) analysis that both "dative- $n i$ accusative- $o$ " and "accusative- $o$ dative- $n i$ " orders are base-generated. Alternatively, Matsuoka's (2003) analysis would predict that anaphors in (21b) are properly bound by their antecedents more often than those in (21d) for pass-type verbs, and that anaphors (21d) are properly bound more often than those in (21b) for show-type verbs.

Because the anaphor soitu in Hoji's example is quite colloquial and is not seen often in written contexts, it was thought that the mere presence of soitu in the sentence items would deteriorate the grammaticality. Therefore, for anaphors that referred to human beings, 'kare-ra' (kare: lit. he; ra: plural morpheme) was used instead. For anaphors that referred to inanimate items in the sentence, 'sore' (lit. it) was used. (Note 2) The pass-type verbs used in the sentence items were watasu ('pass'), butukeru ('throw'), kaesu ('return'), todokeru ('deliver'), and the show-type used were miseru ('show'), abiseru ('pour'), kiseru ('dress'), and sazukeru ('award'). Because there were $-n i-o /-o-n i$ pairs, the participants were asked to make judgments on a total of sixteen sentences in this section.

The last section of the survey attempted to directly assess native Japanese speakers' intuitions on the "dative- $n i$ accusative- $o$ " and "accusative- $o$ dative-ni" word orders of ditransitive sentences. However, directly asking which of the two word orders was more acceptable was expected to cause confusion and difficulty to the participants because both " $\mathrm{S}$ dative- $n i$ accusative- $o \mathrm{~V}$ " and "S accusative- $o$ dative- $n i \mathrm{~V}$ " are used quite frequently. Therefore, the participants were asked to rank-order the following set of sentences:

$$
\begin{aligned}
& \text { a. NP-ga NP-ni NP-o V. } \\
& \text { b. NP-ni NP-o NP-ga V. } \\
& \text { c. NP-o NP-ni NP-ga V. }
\end{aligned}
$$

(22a) is canonical, and (22b) and (22c) are its scrambled counterparts. In (22b), "dative-ni accusative-o" was fronted before the nominative NP, while "accusative- $o$ dative- $n i$ " was fronted in (22c). As Shibatani (1990) points out, scrambling two or more constituents of a sentence results in reduced grammaticality (cf., (4) above). It was hoped, therefore, that the participants' intuition about the $-n i-O /-O-n i$ orders would be assessed more clearly by having them rank-order the "reduced grammaticality" versions of the sentences. Hoji's (1985) analysis predicts that (22b) is ranked higher than (22c), while Miyagawa's (1997) analysis predicts no significant difference in ranking between the two word orders. Alternatively, Matsuoka's (2003) analysis predicts that (22c) is ranked higher than (22b) for sentences with passtype verbs and that (22b) is ranked higher than (22c) for sentences with show-type verbs.

The pass-type verbs used in the last section of the survey were watasu ('pass'), butukeru ('throw'), todokeru ('deliver'), and the show-type verbs used were miseru ('show'), abiseru ('pour'), and oshieru ('teach'). Thus, the participants were asked to rank-order six sets of sentences. The presentation order of three sentences in each set was pseudo-randomized.

The survey was posted on an Internet-based survey service. Twenty-seven native speakers of Japanese living either in Japan or in the U.S. participated in the survey. (However, some participants skipped some question items or an entire section, and thus, not all the items received twenty-seven responses. In such cases, the values were treated as missing.) 


\subsection{Results}

The result summary of the first section of the survey is provided in Table 1 below. A 5-point Likert scale was used to assess the grammaticality of the sentences in this section (5 - no problem as a Japanese sentence; 1 - totally unacceptable as a Japanese sentence). The numbers under the scale indicate the raw frequencies of the ratings that sentences in each category received.

Table 1. Raw response frequencies for the first section of the survey

\begin{tabular}{lllllll}
\hline Likert Scale & & $\mathbf{5}$ & $\mathbf{4}$ & $\mathbf{3}$ & $\mathbf{2}$ & $\mathbf{1}$ \\
\hline Pass-type & NP-ni NP-o & 0 & 9 & 2 & 33 & 34 \\
& NP-o NP-ni & 0 & 6 & 2 & 35 & 35 \\
\hline Show-type & NP-ni NP-o & 0 & 8 & 1 & 36 & 32 \\
& NP-o NP-ni & 0 & 8 & 0 & 39 & 28 \\
\hline
\end{tabular}

Miyagawa (1997) observes that when a numeral quantifier (NQ) is associated with the -ni marked NP in a distansitive sentence with the "NP- $n i$ NP-o" order, the sentence is quite grammatical, and that the grammaticality of the sentence deteriorates when an NQ is associated with the $-n i$ marked NP in a sentence with the "NP-o NP-ni" order. The result of the survey, however, indicated that the sentences with NQs generally received rather low acceptability and that there was no significant difference in acceptability between the "NP- $n i$ NP- $o$ " and "NP- $o$ NP-ni" orders based on a Wilcoxon $t$-test $(p=.559, n$.s. $)$. While Miyagawa maintains that $-n i$ in the "NP- $n i \mathrm{NP}-o$ " order is a case-marker and that $-n i$ in the "NP-o NP-ni" is a postposition, the results above did not seem to support such a distinction.

For the purpose of examining the effects of word order $(-n i-o /-o-n i)$ and of verb type (pass/show), pairwise Wilcoxon $t$-tests were conducted. However, no significant differences were observed. Therefore, the first section of the survey did not observe any effects of word order or of verb type.

The result summary of the second section of the survey is presented in Tables 2 and 3 below. For scoring, when the participants responded that the anaphor referred to the antecedent in the same sentence $o r$ that the anaphor referred to the antecedent in the same sentence and something/someone else, it was taken as evidence that the sentence allowed the co-indexed reading, and the score of " 1 " was given to the response. On the other hand, when the participants responded that the anaphor referred to something or someone other than the antecedent in the same sentence, it was interpreted that the co-indexed reading was not allowed for the sentence, and the score of " 0 " was given to the response. Table 2 shows the raw frequencies of instances in which the binding relationships were allowed. The values in parentheses show the total number of responses for each sentence type. Table 3 presents percentages of instances in which the co-indexed readings were allowed.

Table 2. Raw frequencies of instances when the co-indexed readings were allowed

\begin{tabular}{l|llll}
\hline & $\begin{array}{l}\text { Antecedent-ni } \\
\text { Anaphor-o }\end{array}$ & $\begin{array}{l}\text { Anaphor-ni } \\
\text { Antecedent-o }\end{array}$ & $\begin{array}{l}\text { Antecedent-o } \\
\text { Anaphor-ni }\end{array}$ & $\begin{array}{l}\text { Anaphor-o } \\
\text { Antecedent-ni }\end{array}$ \\
\hline Pass-type & $38(54)$ & $24(54)$ & $38(52)$ & $20(53)$ \\
Show-type & $35(53)$ & $17(54)$ & $36(54)$ & $21(54)$ \\
\hline
\end{tabular}

Table 3. Percentages of instances when the co-indexed readings were allowed

\begin{tabular}{l|llll}
\hline & $\begin{array}{l}\text { Antecedent-ni } \\
\text { Anaphor-o }\end{array}$ & $\begin{array}{l}\text { Anaphor-ni } \\
\text { Antecedent-o }\end{array}$ & $\begin{array}{l}\text { Antecedent-o } \\
\text { Anaphor-ni }\end{array}$ & $\begin{array}{l}\text { Anaphor-o } \\
\text { Antecedent-ni }\end{array}$ \\
\hline Pass-type & 70.37 & 44.44 & 73.08 & 37.74 \\
Show-type & 66.04 & 31.48 & 66.67 & 38.89 \\
\hline
\end{tabular}

As expected, the participants accepted the co-indexed reading more often when antecedents preceded anaphors. Hoji (1985) maintained, based on the assumption that " $-n i-O$ " is the base-generated word order for ditransitive sentences, that the "anaphor- $n i$ antecedent- $o$ " order is ungrammatical while the "anaphor- $o$ antecedent- $n i$ " order is marginally acceptable. However, according to a Wilcoxon signed-ranks test, no such difference in grammaticality was observed between the two orders $(p=1, n . s$.).

Although not statistically significant, and thus only suggestive, one very interesting point to note is that the acceptability of the "anaphor- $n i$ antecedent- $o$ " and "anaphor- $o$ antecedent-ni" sentences seems to follow Matsuoka's (2003) hypothesis of two verb types. According to Matsuoka, the acceptability of the "anaphor- $n i$ antecedent- $O$ " order should be higher than the "anaphor-o antecedent-ni" order for pass-type verbs, because pass-type verbs base-generate the "- $o-$ ni" order. On the other hand, Matsuoka's analysis predicts the opposite for show-type verbs because show-type verbs base-generate the "-ni-o" order. The data in Tables 2 and 3 seem to show tendencies that correspond to Matsuoka's analysis. 
The result of the third section of the survey is summarized in Table 4. The task was to rank-order the sentences with the "NP-ga NP-ni NP-o", "NP-ni NP-o NP-ga" and "NP-o NP-ni NP-ga" orders using 1, 2, and 3. For data analysis, the rank numbers 1,2 , and 3 were quantified as 1,2, and 3, respectively. The numbers in Table 4 are the raw frequencies of the rank orders that the sentences in each category received.

Table 4. Rank orders that the sentences in each category received

\begin{tabular}{llccc}
\hline Rank Order & & $\mathbf{1}$ & $\mathbf{2}$ & $\mathbf{3}$ \\
\hline Pass-type & NP-ga NP-ni NP-o & 81 & 0 & 0 \\
& NP-ni NP-o NP-ga & 0 & 50 & 31 \\
& NP-o NP-ni NP-ga & 0 & 31 & 50 \\
\hline Show-type & NP-ga NP-ni NP-o & 78 & 3 & 0 \\
& NP-ni NP-o NP-ga & 3 & 48 & 30 \\
& NP-o NP-ni NP-ga & 0 & 30 & 51 \\
\hline
\end{tabular}

While there was no significant difference in terms of verb types, a Wilcoxon $t$-test showed that the "NP-ni NP-o NP-ga" order was ranked significantly higher than the "NP-o NP-ni NP-ga" order $(p=.009)$. Thus, the result of the third section of the survey seems to support Hoji's (1985) analysis that "NP-ga NP- $n i$ NP-o" is the canonical word order for ditransitive sentences regardless of verb types.

\section{Discussion}

The results of the survey were somewhat conflicting. While the result of the third section seems to support Hoji's (1985) analysis, as Koizumi and Tamaoka's (2004) psycholinguistic study did, the second section did not provide support for Hoji's view. Instead, although just suggestive, the data from the second section seem to exhibit tendencies that correspond to Matsuoka's (2003) analysis. The result of the first section did not seem to support Miyagawa's (1997) analysis that $-n i$ in the "NP-ni NP-o" order is a case-marker and that $-n i$ in the "NP-o NP-ni" is a postposition.

The acceptability of the sentences with a numeral quantifier was surprisingly low in the first section of the survey. Many participants chose " 1 - totally unacceptable as a Japanese sentence" although the investigator (a native speaker of Japanese) felt that the sentences were, at least, marginally acceptable.

There may be a few reasons for this. The first reason may be attributed to the pause or intonation the participants used while mentally reading the sentences. While the sentences were presented in Japanese script without any commas, it is still possible to place a pause in the sentences in the following way:

$$
\begin{gathered}
\text { a. Mary-ga tomodati-ni futa-ri, CD-o watashita. } \\
\text {-Nom friend-Dat 2-CL CD-Acc passed } \\
\text { 'Mary passed CDs to two friends.' }
\end{gathered}
$$

b. Mary-ga tomodati-ni, futa-ri CD-o watashita.

If a pause is placed after the NQ as in (23a), the sentence is grammatical. However, the same sentence becomes unacceptable if a pause is placed between the $-n i$ marked NP and the quantifier. It is so probably because now the NQ is associated with the $-O$ marked NP, in which case a different classifier is required to make the sentence grammatical. Thus, if the participants consistently assigned a mental pause after the $-n i$ marked NP, it is possible that all the sentences in this section were judged unacceptable.

Another possible reason for the low acceptability of the sentences is the varying definition of "acceptability" for each participant. That is, it is possible some participants decided that a sentence was unacceptable because they themselves do not often use or hear the sentence. If their judgment was based on a criterion such as "I wouldn't use this sentence", then the results of the survey could be quite different from what linguists call grammaticality judgment. (Note 3)

There might have been a similar problem for the question items in the second section. What the investigator wanted to observe in this section was whether the bound reading of anaphors would be impossible in the "anaphor- $n i$ antecedent$o$ " and "anaphor- $o$ antecedent- $n i$ " orders. The most direct way to elicit responses would have been to ask if the sentence would be grammatical when the antecedent and the anaphor were co-indexed. However, because the co-index notations were likely to cause confusion to the participants, an alternative "indirect" method - "What does this word refer to?" was used. While it is hoped that the method successfully elicited the intended responses, due to its indirectness, it is possible that the responses were a reflection of the participants' preferences rather than their grammatical judgment. For instance, when a participant chose the response "the anaphor refers to something other than the antecedent", it does not necessarily mean that the participant judged the sentence to be ungrammatical when the anaphor was bound by the antecedent. It could have been merely his preference. Thus, an alternative method could have elicited more relevant responses for the research question.

An interesting observation in the second section of the survey is that quite a few responses (approximately 40\%) indicated that an anaphor can refer to an antecedent in ditransitive sentences even when the anaphor precedes the antecedent, similarly to Saito's example (3d) above. From this observation, due to the extensive use of scrambling and 
null anaphora in Japanese, it can be surmised that native speakers of Japanese have learned to establish antecedentanaphor relationships in the reversed "anaphor-antecedent" order, when such an interpretation is possible from the context. In this respect, Miyagawa's (1997) analysis that both "-ni-o" and "- $o-n i$ " orders are base-generated appears quite plausible.

The third section of the survey indicated that the "NP- $n i$ NP-o NP- $g a$ " order was preferred to the "NP-o NP- $n i$ NP- $g a$ ", supporting Hoji's (1985) analysis. One possible problem with the procedure, however, is that these target sentences were presented with the "NP-ga NP- $n i$ NP-o" sentences but not with the "NP-ga NP-o NP-ni" sentences. Therefore, it is possible that this presentation bias influenced the preference of the $-n i-o$ order over the $-o-n i$ order. Therefore, the result should be interpreted with caution, and a future replication study with an improved design would be necessary.

In addition to the several limitations of the survey study already mentioned, perhaps the largest limitation of the present study comes from the fact that the number of the items used in the study was very small. Due to the small number of items in each sentence condition, it is possible that the relative weight of each item was too large to obtain definitive results. Yet another problem might have come from the items themselves. Although the sentence items were created with the investigator's best possible judgments, they were not evaluated by other native speakers of Japanese prior to the survey. Such a norming procedure could have increased the reliability of the study.

What is the canonical word order for Japanese ditransitive sentences after all? While a part of the survey supported Hoji's (1985) analysis, there was also suggestive evidence that support the analyses by Matsuoka (2003) and Miyagawa (1997). The answer is inconclusive in the present survey study. A future study with a larger number of items and more refined research methods, along with more studies from structural and psycholinguistic perspectives, would be necessary to clarify the point.

An interesting research method to investigate the issue is brain imaging. Kim et al. (2009) found that there is more activity in some areas of the brain (the left inferior frontal gyrus and the left dorsal prefrontal cortex) during the comprehension of scrambled sentences than during the comprehension of canonical sentences. Although the results of Kim et al. are based on the processing of simple transitive sentences (NP-ga NP-o V), the same method may be used to investigate brain activity during the comprehension of ditransitive sentences. While increased brain activity may not necessarily correspond to the processing of scrambled sentences, such a study would provide important clues in the investigation of the canonical word order of Japanese ditransitive sentences.

\section{References}

Baker. M. (1995). On the structural positions of themes and goals. In J. Rooryck \& L. Zauring (Eds.), Phrase structure and the lexicon (pp. 7-34). Dordrecht: Kluwer.

Chomsky, N. (1995). The minimalist program. Cambridge, MA: MIT Press.

Farmer, A. K. (1984). Modularity in syntax: A study of Japanese and syntax. Cambridge, MA: MIT Press.

Haig, J. (1980). Some observations on quantifier float in Japanese. Linguistics, 18, 1065-1083.

Hale, K. (1980). Remarks on Japanese phrase structure: Comments on the papers on Japanese syntax. MIT Working Papers in Linguistics, 2, 185-203.

Hoji, H. (1985). Logical form constraints and configurational structures in Japanese. Doctoral dissertation, University of Washington, Seattle.

Kim, J., Koizumi, M., Ikuta, N., Fukumitsu, Y., Kimura, N., Iwata, K., .. Kawashima, R. (2009). Scrambling effects on the processing of Japanese sentences: An fMRI study. Journal of Neurolinguistics, 22, 151-166.

Kitagawa, Y. (1994). Shells, yolks, and scrambled e.g.s. Proceedings of the $24^{\text {th }}$ Conference of the Northeast Linguistic Society, University of Massachusetts, Amherst, 221-239.

Koizumi, M., \& Tamaoka, K. (2004). Cognitive processing of Japanese sentences with ditransitive verbs. Gengo Kenkyu, 125, 173-190.

Matsumoto, Y. (2000). Osowaru/osieru nadono tadoosi/nizyuutadoosi-pea-no imiteki seisitu [Semantic properties of pairs of transitive/ditransitive verbs such as osowasu/osieru 'get taught/teach']. In S. Yamada, Y. Kikuchi, \& Y. Moriyama (Eds.), Nihongo: Imi-to-bunpoo-no fuukei (pp. 79-95). Tokyo: Hituzi Syobo.

Matsuoka, M. (2003). Two types of ditransitive constructions in Japanese. Journal of East Asian Linguistics, 12, 171203.

Mazuka, R., Itoh, K., \& Kondo, T. (2002). Cost of scrambling in Japanese sentence processing. In M. Nakayama (Ed.), Sentence processing in East Asian languages (pp. 131-166). Stanford, CA: CSLI.

Miyagawa, S. (1997). Against optional scrambling. Linguistic Inquiry, 28, 1-25.

Nemoto, N. (1999). Scrambling. In N. Tsujimura (Ed.), The handbook of Japanese linguistics (pp. 121-153). Malden, MA: Blackwell.

Rizzi, L. (1986). On chain formation. In H. Borer (Ed.), Syntax and semantics 19: The syntax of pronominal clitics (pp. 65-96). New York: Academic Press.

Saito, M. (1985). Some asymmetries in Japanese and their theoretical implications. Unpublished doctoral dissertation, 
Massachusetts Institute of Technology, Cambridge, MA.

Saito, M., \& Hoji, H. (1983). Weak cross-over and move $\alpha$ in Japanese. Natural Language \& Linguistic Theory, 1, $245-$ 259.

Shibatani, M. (1990). The languages of Japan. Cambridge: Cambridge University Press.

Takano, Y. (1998). Object shift and Scrambling. Natural language and linguistic theory, 16, 817-889.

Tamaoka, K., Sakai, H., Kawahara, J., Miyaoka, Y., Lim, H., \& Koizumi, M. (2005). Priority information used for the processing of Japanese sentences: Thematic roles, case particles or grammatical functions? Journal of Psycholinguistic Research, 34, 281-332.

Yamashita, H. (1997). The effects of word-order and case marking information on the processing of Japanese. Journal of Psycholinguistic Research, 26, 163-188.

Yamashita, H. (2002). Scrambled sentences in Japanese: Linguistic properties and motivations for production. Interdisciplinary Journal for the Study of Discourse, 22 (4), 597-633.

\section{Notes}

Note 1. Matsuoka (2003) does not claim that all ditransitive verbs in Japanese can be classified into one of these two verb types. Not all Japanese ditransitive verbs have inchoative variants.

Note 2. Alternatively, the anaphor sore-ra (sore: lit. it; ra: plural morpheme) could have been used to refer to inanimate items. However, after consulting a few native speakers of Japanese, it was felt that sore-ra is not as commonly used as kare-ra. Therefore, it was decided to use sore.

Note 3. For instance, a participant might hear or use "tomidati futa-ri-ni" (friend two-CL-Dat) more frequently than "tomodati-ni futa-ri" as in (23). In such a case, any sentences that include the "NP-Dat number-CL" sequences might consistently receive lower ratings. 